\title{
UNIFORM BOUNDS FOR EXPRESSIONS INVOLVING MODIFIED BESSEL FUNCTIONS
}

\author{
RoBERT E. GAUnT
}

Abstract. In this paper, we obtain uniform bounds for a number of expressions that involve integrals of modified Bessel functions. These uniform bounds are motivated by the need to bound such expressions in the study of variance-gamma and product normal approximations via Stein's method.

Mathematics subject classification (2010): 33C10.

Keywords and phrases: Modified Bessel functions.

\section{REFERENCES}

[1] Á. BARICZ, On a product of modified Bessel functions, Proc. Amer. Math. Soc. 137 (2009), 189-193.

[2] Á. BARICZ, Bounds for Turánians of modified Bessel functions, Expo. Math. 33 (2014), 223-251.

[3] Á. Baricz, D. Jankov Maširević, S. Ponnusamy And S. Singh, Bounds for the product of modified Bessel functions, arXiv:1511:06082, (2015).

[4] R. E. GAunT, Rates of Convergence of Variance-Gamma Approximations via Stein's Method, DPhil thesis, University of Oxford, (2013).

[5] R. E. GAUNT, On Stein's method for products of normal random variables and zero bias couplings, Bernoulli, to appear.

[6] R. E. Gaunt, Variance-Gamma approximation via Stein's method, Electron J. Probab. 19, no. 38 (2014), 1-33.

[7] R. E. GAUnT, Inequalities for modified Bessel functions and their integrals, J. Math. Anal. Appl. 420 (2014), 373-386.

[8] I. S. Gradshetyn And I. M. Ryzhik, Table of Integrals, Series and Products, Academic Press, 7 th ed, 2007.

[9] P. HARTMAn, On the products of solutions of second order disconjugate differential equations and the Whittaker differential equation, SIAM J. Math. Anal. 8 (1977), 558-571.

[10] A. L. Jones, An extension of an inequality involving modified Bessel functions, J. Math. Phys. 47 (1968), 220-221.

[11] I. NÅsELL, Inequalities for Modified Bessel Functions, Math. Comput. 28 (1974), 253-256.

[12] F. W. J. Olver, D. W. Lozier, R. F. Boisvert AND C. W. Clark (Eds), NIST Handbook of Mathematical Functions, Cambridge University Press, 2010.

[13] J. SEgurA, Bounds for ratios of modified Bessel functions and associated Turán-type inequalities, J. Math. Anal. Appl. 374 (2011), 516-528. 